\title{
Influence of Active \& Passive Warming Up On Motor Performance of the Athletes
}

\author{
Dr. Subhabrata Kar, Prof. Alok K. Banerjee \\ Assistant Professor, Union Christian Training College, Berhampore, Murshidabad, W.B. \\ Professor in Physical Education and Ex. Dean, Faculty of Education, University of Kalyani, Kalyani, Nadia, \\ West Bengal, India.
}

\begin{abstract}
Introduction: Participating in some form of a warming up prior to engaging in physical activity is considered an acceptable and valid practice. Nonetheless, the topic has been debated among those in the sport and physical education field for a number of years. The present study was framed to find out the influence of various types active and passive of warming up methods on trained and untrained subjects.

Methods: Two categories of persons were taken as subjects for the study. The first category was comprised of active trained athletes participating in sports and games for more than 5 years and they are called trained athletes or TA. The second category was comprised of Physical Education trainee students of without any sports back-ground $(N=26)$ and of age group 20-25 years and they will be called Physical Education less active group i.e. PELA.

Motor performance of the subjects was measured through strength, agility and flexibility components and that components were measured by Pull-ups tests, Shuttle run test and Sit and Reach test (modified) respectively. Here five conditions were introduced to test the performances of the subjects, which were No warming up $(N W U)$, Active unrelated warming up (AUR), Active related Warming up (AR), and Sauna bath (SB) and Massage (MAS). All the subjects took part in each of the test once without warming-up and again after due warming-up.

The data was analyzed by appropriate statistical method.

Results and Discussion: It was found that both active and passive warming-up had significant influence on motor performances of both trained and untrained subjects, but the percentage of influence varied according to their performance status. At the same time it was also found that influence of warming up varied in respect of motor components.

Conclusion: It may finally be concluded that for TA active and passive WU has some influence on motor performance in respect of $N W U$, but this influence is not significant for all cases. The mean magnitude of increment of sit and reach performance due to active as well as passive WU is found low due to extreme performance by some subjects in NWU case.
\end{abstract}

Key Words: Warming-up, Active and Passive WU, Motor Performance, Trained and Untrained.

\section{Introduction}

Participating in some form of a warming up prior to engaging in physical activity is considered an acceptable and valid practice. Nonetheless, the topic has been debated among those in the sport and physical education field for a number of years. Some professionals believe warming-up is essential to physical activity, while others believe warming-up is not necessary.

However, there are numerous physiological advantages associated with a warming-up that are difficult to refute. A warming-up is usually performed before participating in technical sports or exercising.A warmingup generally consists of a gradual increase in intensity in physical activity (pulse raiser), a joint mobility exercise, stretching and a sport related activity. For example, before running or playing an intense sport one might slowly jog to warm muscles and increase heart rate. It is important that warming ups should be specific to the exercise that will follow, which means that exercises (of warming up) should prepare the muscles to be used and to activate the energy systems that are required for that particular activity. The risks and benefits of combining stretching with warming up are mixed and in some cases disputed. Warming up prepares the body mentally and physically. Edington and Egerton state: 'Warming-up is a technique to prepare the body for exercise at a competitive rate'.

There are some historical evidence regarding practice of warming-up in ancient times that ancient Greeks believed that training and music should be experienced together because they both pleased man's spirit and music was a key part of their warm up (Stefanovic et al.112). The athletic training of Greeks differed depending on whether it was held in indoors or outdoors, in hot or cold weather, on wet or dry days. In the ancient Greco-Roman tradition, wrestling warming-up drills were very important. Warming-up drills got one's 
body's systems going, his blood flowing, and his body was being ready for the upcoming challenges. Different researchers like Asmussen and Boje (1945), Gregson, et al.(2002), Grose (1958), Bergh and Ekblom (1979) and so on studied the performance of trained, moderately trained and untrained male under various WU conditions and they showed performance increment in sprint time, peak velocity, average speed at exercise, hot water shower, hot bath, diathermy etc in comparison to no WU. Bishop, (2003) concluded after reviewing different studies that active warming up tends to improve slightly larger improving in short-term performance $(<10$ seconds) than those achieved by passive heating alone. In another study they suggested that supra-maximal sprints were improved by including a judicious amount of specific supra-maximal sprinting in warm-up.

Curry, et al. (2009) suggested that the variation in responses to warm-up conditions emphasizes the unique nature of individual reactions to different warm-ups; however, there was a tendency for warm-ups with an active component to have beneficial effects. The data suggests dynamic stretching has greater applicability to enhance performance on power outcomes compared to static stretching in trained only.

Close, 1995; Barany, 1967; Gray, et al., 2006 suggested that muscles must be warmed up in order to contract as fast as possible. At the same time Bishop (2003) suggested that a warm muscle reduces the viscosity leading to more efficient contraction. Different researchers like Asmussen and Boje (1945), Gregson, et al.(2002), Grose (1958), Bergh and Ekblom (1979), Binkhorst, et al. (1977), Clerk, et ai. (1958), Davies and Young (1983), Ranatunga, et al.(1980), Grose (1958) and so on studied the performance of trained, moderately trained and untrained male under various WU conditions and they showed performance increment in isometric force, vertical jump height, hand grip strength, finger strength, knee extension etc at exercise, hot water shower, hot bath, diathermy etc in comparison to no WU. They also showed best performance increment for trained than moderately trained and untrained. Holmstrom, et al.(2001) suggested that short dose of warming up exercises could be beneficial for increasing and maintaining joint and muscle flexibility and muscle endurance for untrained male workers. Barlow, et al. (2004) suggested that a single massage of hamstring muscle group does not significantly alter Sit \& Reach performance. However, their results also seem to indicate that percentage changes in Sit and Reach scores may be inversely proportional to pre-treatment values. The percentage changes in Sit \& Reach scores were relatively small for those with pre-treatment values of $15 \mathrm{~cm}$. and above -that is, those with relatively long reach to begin with.

\section{Selection of Subjects:}

\section{Methodology}

Two categories of persons were taken as subjects for the study. The first category was comprised of active trained athletes participating in sports and games for more than 5 years and they had participated at least one Inter-University or State Level games and sports of age group 20-25 years $(\mathrm{N}=26)$ and they are called Trained athletes or TA. They were collected from 70 numbers of available subjects. The second category was comprised of Physical Education trainee students of without any sports back-ground $(\mathrm{N}=26)$ and of age group 20-25 years, and they will be called Physical Education less active group i.e. PELA. They were also chosen from 150 available subjects. All the boys were selected randomly from their respective population all over Murshidabad and Nadia district of West Bengal.

\section{Criterion Measure:}

Motor Performance: Motor performance of the subjects was measured through standard motor performance tests. It is to say that, to test the Physical fitness components "AAHPERD Youth Fitness Test" batteries were used, but for researcher's convenience some test batteries were given up as well as some batteries were introduced. Here Motor performance of the subjects was measured through strength, agility and flexibility components and that components were measured by Pull-ups tests, Shuttle run test and Sit and Reach test (modified) respectively.

\section{Group Design:}

There were two main types of warming up- 1. Active Warming-up, 2. Passive Warming-up. Active Warming-up was subdivided into a) Through related activity. b) Through unrelated activity. Another two types of passive warming up had been introduced; those were 'Heating by Sauna bath' and 'Use of Massage'. Therefore, here five conditions were introduced to test the performances of the subjects, which were No warming up (NWU), Active unrelated warming up (AUR), Active related Warming up (AR), Sauna bath (SB) and Massage (MAS).

Both two groups took part in each of the test once without warming-up and again after due warmingup, that is, after following four different types of warming-up. All the 52 subjects were first of all tested without warming up and then they were tested for motor as well as sports performance in different days or same day after at least 4 hours of rest period after following one type of warming up. 
The all possible correlation coefficients (r) among the k groups had been measured. (The homogeneity of covariance assumption requires that all of these correlation coefficients be positive and of approximately the same magnitude). All the correlations were supposed to be positive and more or less high. Essentially, it is a requirement that the differential effects of the $\mathrm{k}$ conditions were consistent among the subjects in the repeated measures design, or among the matched sets of subjects in the randomized blocks design.

The researcher considered the ANOVA of correlated samples. It is the same structure with the correlated- samples ANOVA with two samples, except that now the number of conditions is three or more: NWU|AUR|AR|SB|MAS, and so forth. When the analysis involves each subject being measured under each of the 5 conditions, it is sometimes spoken of as a repeated measures or within subjects design. When it involves subjects matched in sets of three for $\mathrm{k}=3$, four for $\mathrm{k}=4$, and so on, with the subjects in each matched set randomly assigned to one or another of the $\mathrm{k}$ conditions, it is described as a randomized blocks design. (In this latter case, each set of $\mathrm{k}$ matched subjects constitutes a "block.") Thus, for $\mathrm{k}=5$, the investigator had chosen the repeated measure design to analyze the data.

\section{Results and Discussions}

The Mean and SD of performance of TA in pull-ups after no warming-up and four warming-up conditions were $10.0385 \pm 3.143,12.6923 \pm 3.9372,13.1923 \pm 3.8369,12.9231 \pm 3.7194$ and $11.8462 \pm 3.802$ respectively. The overall Mean and SD was found 12.1385 \pm 3.817 . The Mean and SD of performance of PELA in pull-ups after no warming up and four warming up conditions were 9.3077 $\pm 2.4128,10.1154 \pm 2.4872$, $10.2692 \pm 2.5069,10.2692 \pm 3.3589,9.6538 \pm 2.5759$ respectively. The overall mean and SD was found $9.9231 \pm 2.4609$. In case of Shuttle Run the Mean and SD of performance after no warming up and four warming up conditions for TA were $9.2812 \pm 0.3285 \mathrm{sec}$. $9.0796 \pm 0.2587 \mathrm{sec}, 9.0496 \pm 0.2527 \mathrm{sec}, 9.0685 \pm 0.2586 \mathrm{sec}$. and $9.1288 \pm 0.3021 \mathrm{sec}$. respectively. The overall Mean and SD was found $9.1215 \pm 0.2899 \mathrm{sec}$. At the same time the Mean and SD of performance after no warming up and four warming up conditions of PELA were $9.6938 \pm 0.2429 \mathrm{sec}, \quad 9.6742 \pm 0.2348 \mathrm{sec}, \quad 9.6558 \pm 0.2365 \mathrm{sec} ., \quad 9.6646 \pm 0.239 \mathrm{sec}, \quad$ and $9.6781 \pm 0.2396 \mathrm{sec}$. respectively. The overall Mean and SD was found 9.6733 $\pm 0.2352 \mathrm{sec}$. In case of Sit and Reach performance the Mean and SD of TA after no warming up and four warming up conditions were $13.9831 \pm 3.3209 \mathrm{~cm} ., 14.9523 \pm 3.5062 \mathrm{~cm} ., 14.7519 \pm 4.4262 \mathrm{~cm} ., \quad 15.0662 \pm 3.5354 \mathrm{~cm}$. and $14.5831 \pm 3.5536 \mathrm{~cm}$. respectively. The overall Mean and SD was found $14.6673 \pm 3.6512 \mathrm{~cm}$. The Mean and SD of Sit \& Reach performance of PELA after no warming up and four warming up conditions were $13.5038 \pm 4.2545 \mathrm{~cm}$., $13.8831 \pm 4.3093 \mathrm{~cm}$., $\quad 14.1027 \pm 4.4042 \mathrm{~cm}, 14.0569 \pm 4.3856 \mathrm{~cm}$. and $13.9077 \pm 4.3982 \mathrm{~cm}$. respectively. The overall Mean and Variance was found $13.8908 \pm 4.288 \mathrm{~cm}$. Let us now consider the ANOVA of correlated samples. Consulting the tabulated value of $F$ with degrees of freedom 4 and 100, the $F$ ratios needed for significant differences between the means were 2.46 and 3.51 at 0.05 and 0.01 levels respectively. In case of Pull-ups test data for TA the observed value was found to be $\mathbf{F}=57.45$ and for the PELA the observed value was found to be $\mathbf{F}=18.86$. Both the ratios $(\mathrm{F})$ fall far to the right of $\mathbf{F}=3.51$, i.e., our calculated $\mathrm{F}$ was much higher than the tabulated value. Therefore, $F$ was significant. When $F$ was significant then it was said that at least two means were significantly different. Here, Tukey's honestly significant difference (HSD) method was followed for post hoc testing of differences between paired means. While considering Pull-ups test result, it may be noted that for TA mean of NWU was significantly lower than all other four conditions. It means that performance at NWU was lowest in comparison to four other conditions. All the differences between means were found significant at $1 \%$ level. Differences between AUR and AR, AUR and SB as well as AR and SB were not significant at all. In case of PELA, it May be noted that performance at NWU significantly lower than other three Warming up conditions except MAS. Differences between the means of NWU and MAS, AUR and AR, AUR and SB, as well as AR and SB were found not significant at all. In case of Shuttle run test data for TA the observed value was found to be $\mathbf{F}=30.99$ and for the PELA the observed value was found to be $\mathbf{F}=13.46$. Both the ratios $(F)$ fall far to the right of $\mathbf{F}=3.51$, i.e., our calculated $F$ was much higher than the tabulated value. Therefore, F was significant. While considering the Shuttle run test data, on the basis of the Statistical Analysis it might surely be concluded that performance without warming up of TA was significantly lower than all other four conditions. Best performance was observed at AR, but post hoc test showed it was not significantly better than other four conditions except MAS and NWU. On the basis of the Statistical Analysis for PELA it might surely be concluded that performance without warming up was not significantly lower than all other four conditions. It was found lower than performance at AR and SB only. No significant increments were found in case of performance at AUR as well as MAS. In case of Shuttle run test data for TA the observed value was found to be $\mathbf{F}=4.01$ and for the PELA the observed value was found to be $\mathbf{F}=14.31$. Both the ratios $(F)$ fall to the right of $\mathbf{F}=3.51$, i.e., our calculated $\mathrm{F}$ was higher than the tabulated value. Therefore, $\mathrm{F}$ was significant Post HOC test showed that for TA, NWU mean was not always significantly lower than all other four means. Differences between the means of NWU and AR, NWU and SB, NWU and MAS, AUR and AR, AUR and SB, AUR and MAS, AR and SB and MAS as well as SB and MAS were not significant at all. In case of PELA it 
was showed that that performance without warming up was significantly lower than all other four conditions, but differences between the means of AUR and AR, AUR and SB, AUR and MAS, AR and SB, AR vs MAS as well as SB and MAS were found insignificant at all. Performance without warming up is significantly lower than all other four conditions for TA and PEA so far as pull ups performance is concerned.

Table: 1-Mean and S.D. of Pull-ups performance of two groups after NWU and other WU conditions.

\begin{tabular}{|c|c|c|c|c|c|c|}
\hline $\begin{array}{c}\text { WU } \\
\text { Type } \\
\text { s }\end{array}$ & NWU & ARU & AR & SB & MAS & OL \\
\hline $\begin{array}{c}\text { TA } \\
\text { group }\end{array}$ & $10.0385 \pm 3.143$ & $12.6923 \pm 3.9372$ & $13.1923 \pm 3.8369$ & $12.9231 \pm 3.7194$ & $11.8462 \pm 3.802$ & 12.1385 \\
\hline $\begin{array}{c}\text { PEL } \\
\text { A } \\
\text { group }\end{array}$ & $9.3077 \pm 2.4128$ & $10.1154 \pm 2.4872$ & $10.2692 \pm 2.5069$ & $10.2692 \pm 3.3589$ & $9.6538 \pm 2.5759$ & $9.9231 \pm$ \\
\hline
\end{tabular}

Table: 2-Mean and S.D. of Shuttle run performance of two groups after NWU and other WU conditions.

\begin{tabular}{|l|l|l|l|l|l|l|}
\hline WU Types & NWU & AUR & AR & SB & MAS & OL \\
\hline TA group & $\begin{array}{l}9.2812 \pm 0 \\
.3285\end{array}$ & $9.0796 \pm 0.2587$ & $9.0496 \pm 0.2527$ & $9.0685 \pm 0.2586$ & $9.1288 \pm 0.3021$ & $\begin{array}{l}9.1215 \pm 0.28 \\
99\end{array}$ \\
\hline $\begin{array}{l}\text { PELA } \\
\text { group }\end{array}$ & $\begin{array}{l}9.6938 \pm 0 \\
.2429\end{array}$ & $9.6742 \pm 0.2348$ & $9.6558 \pm 0.2365$ & $9.6646 \pm 0.239$ & $9.6781 \pm 0.2396$ & $\begin{array}{l}9.6733 \pm 0.23 \\
52\end{array}$ \\
\hline
\end{tabular}

Table: 3-Mean and S.D. of Sit \& Reach performance of two groups after NWU and other WU conditions.

\begin{tabular}{|c|c|c|c|c|c|c|}
\hline $\begin{array}{l}\text { WU } \\
\text { Types }\end{array}$ & NWU & AUR & AR & SB & MAS & $\mathrm{OL}$ \\
\hline $\begin{array}{l}\text { TA } \\
\text { group }\end{array}$ & $\begin{array}{l}13.9831 \pm 3 . \\
3209\end{array}$ & $\begin{array}{l}14.9523 \pm 3.506 \\
2\end{array}$ & $\begin{array}{l}14.7519 \pm 4.426 \\
2\end{array}$ & $\begin{array}{l}15.0662 \pm 3.535 \\
4\end{array}$ & $\begin{array}{l}14.5831 \pm 3.553 \\
6\end{array}$ & $\begin{array}{l}14.6673 \pm 3.651 \\
2\end{array}$ \\
\hline $\begin{array}{l}\text { PELA } \\
\text { group }\end{array}$ & $\begin{array}{l}13.5038 \pm 4 . \\
2545\end{array}$ & $\begin{array}{l}13.8831 \pm 4.309 \\
3\end{array}$ & $\begin{array}{l}14.1027 \pm 4.404 \\
2\end{array}$ & $\begin{array}{l}14.0569 \pm 4.385 \\
6\end{array}$ & $\begin{array}{l}13.9077 \pm 4.398 \\
\end{array}$ & $13.8908 \pm 4.288$ \\
\hline
\end{tabular}

Table No.-4 ANOVA Table for Pull ups test samples for TA.

\begin{tabular}{|l|l|l|l|l|l|}
\hline Source & SS & df & MS & F & P \\
\hline Treatment(Between groups) & 169.7385 & 4 & 42.4346 & $57.45^{*}$ & $<0.0001$ \\
\hline Error & 73.8615 & 100 & 0.7386 & & \\
\cline { 1 - 3 } Ss/Bl & 1635.9077 & 25 & & & \\
\cline { 1 - 3 } Total & 1879.5077 & 129 & & & \\
\cline { 1 - 3 } & &
\end{tabular}

* Significant, F $(4,100)=2.46(5 \%), 3.51(1 \%)$

Table No:5 ANOVA for Pull ups test data for PELA.

\begin{tabular}{|l|l|l|l|l|l|}
\hline Source & SS & Df & MS & F & P \\
\cline { 1 - 5 } Treatment(Between groups) & 18.9231 & 4 & 4.7308 & $18.86^{*}$ & $<.0001$ \\
\hline Error & 25.0769 & 100 & 0.2508 & & \\
\cline { 1 - 3 } Ss/B1 & 737.2308 & 25 & & & \\
\cline { 1 - 3 } Total & 781.2308 & 129 & & & \\
\hline
\end{tabular}

Table No.-6 ANOVA Table for $4 \times 10 \mathrm{~m}$. Shuttle Run test for TA.

\begin{tabular}{|l|l|l|l|l|l|}
\hline Source & SS & Df & MS & F & P \\
\hline Treatment(Between groups) & 0.9172 & 4 & 0.2293 & $30.99 *$ & $<0.0001$ \\
\hline Error & 0.7446 & 100 & 0.0074 & & \\
\hline Ss/B1 & 9.1759 & 25 & & & \\
\hline Total & 10.8377 & 129 & & & \\
\hline
\end{tabular}

$*$ Significant, $\mathrm{F}(4,100)=2.46(5 \%), 3.51(1 \%)$ 
Influence of active \& passive warming up on motor performance of the athletes

Table No:7 ANOVA table for 4x10m Shuttle Run test of PELA.

\begin{tabular}{|l|l|l|l|l|l|}
\hline Source & SS & Df & MS & F & P \\
\hline Treatment(Between groups) & 0.0215 & 4 & 0.0054 & $13.46^{*}$ & $<.0001$ \\
\hline Error & 0.0398 & 100 & .0004 & & \\
\hline Ss/Bl & 7.0755 & 25 & & & \\
\hline Total & 7.1369 & 129 & & & \\
\hline
\end{tabular}

* Significant, $\mathrm{F}(4,100)=2.46(5 \%), 3.51(1 \%)$

Table No.- 8 ANOVA Table for Sit \& Reach test of TA.

\begin{tabular}{|l|l|l|l|l|l|}
\hline Source & SS & df & MS & F & P \\
\hline Treatment(Between groups) & 18.791 & 4 & 4.6977 & $4.01^{*}$ & 0.004654 \\
\hline Error & 117.1504 & 100 & 1.1715 & & \\
\cline { 1 - 3 } Ss/Bl & 1583.8372 & 25 & \multicolumn{3}{|l}{} \\
\cline { 1 - 3 } Total & 1719.7786 & 129 & & & \\
\cline { 1 - 3 }
\end{tabular}

* Significant, F $(4,100)=2.46(5 \%), 3.51(1 \%)$

Table No:9 ANOVA Table for Sit \& Reach performance of PELA.

\begin{tabular}{|l|l|l|l|l|l|}
\hline Source & SS & df & MS & F & P \\
\hline Treatment(Between groups) & 5.7869 & 4 & 1.4467 & $14.31^{*}$ & $<.0001$ \\
\hline Error & 10.1123 & 100 & 0.1011 & & \\
\cline { 1 - 3 } Ss/Bl & 2356.0304 & 25 & \multicolumn{2}{|l}{} \\
\hline Total & 2371.9296 & 129 & &
\end{tabular}

* Significant, F $(4,100)=2.46(5 \%), 3.51(1 \%)$

\section{Fig No.1: Mean Performance in Pull ups of two groups after NWU and different} types of WUs.

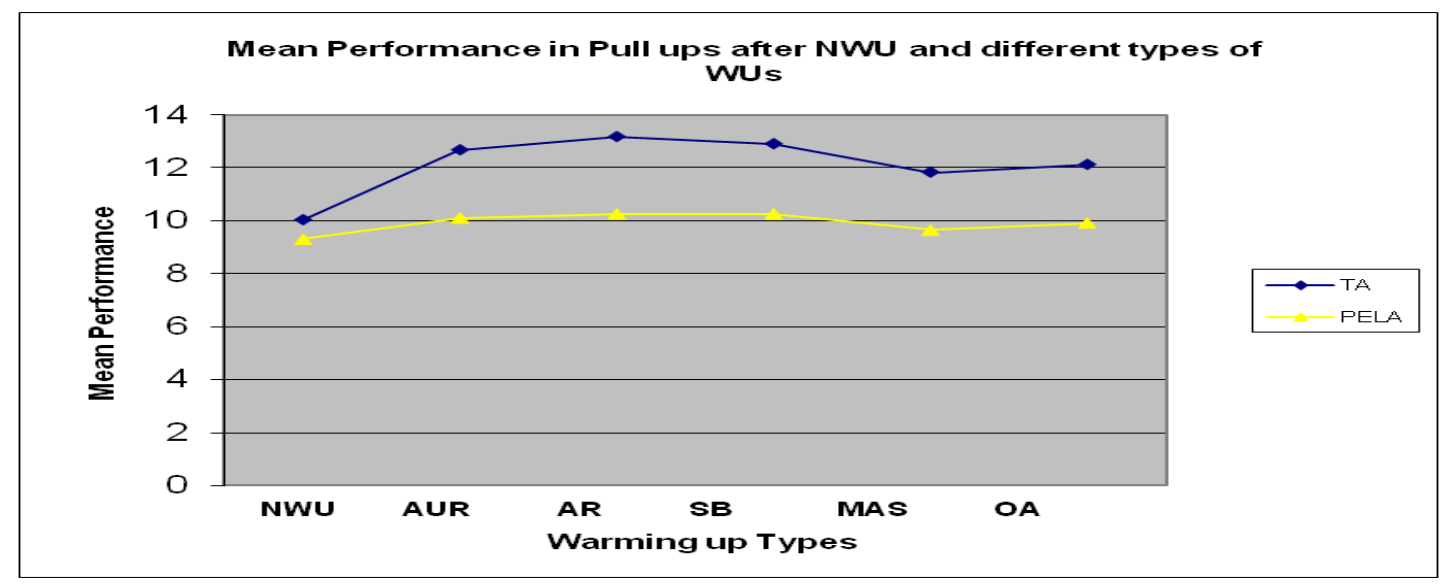

Fig No.2: Mean Performance in Shuttle run of two groups after NWU and different types of WUs.

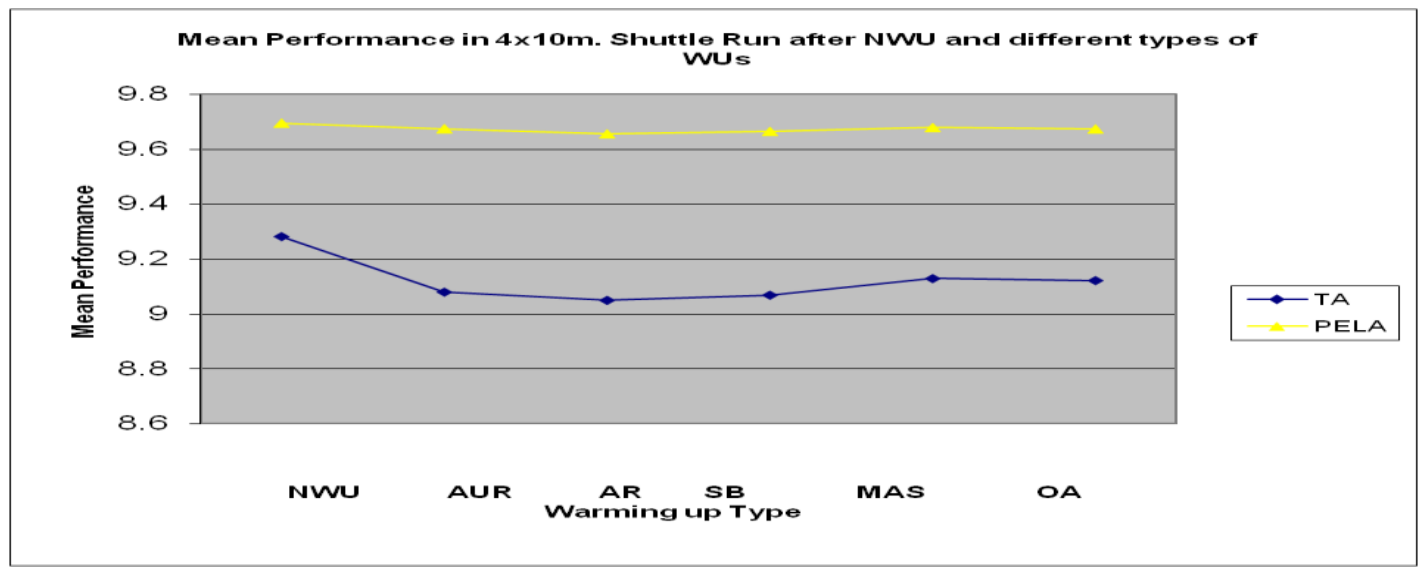


Fig No.3: Mean Performance in Sit \& Reach of two groups after NWU and different Types of WUs.

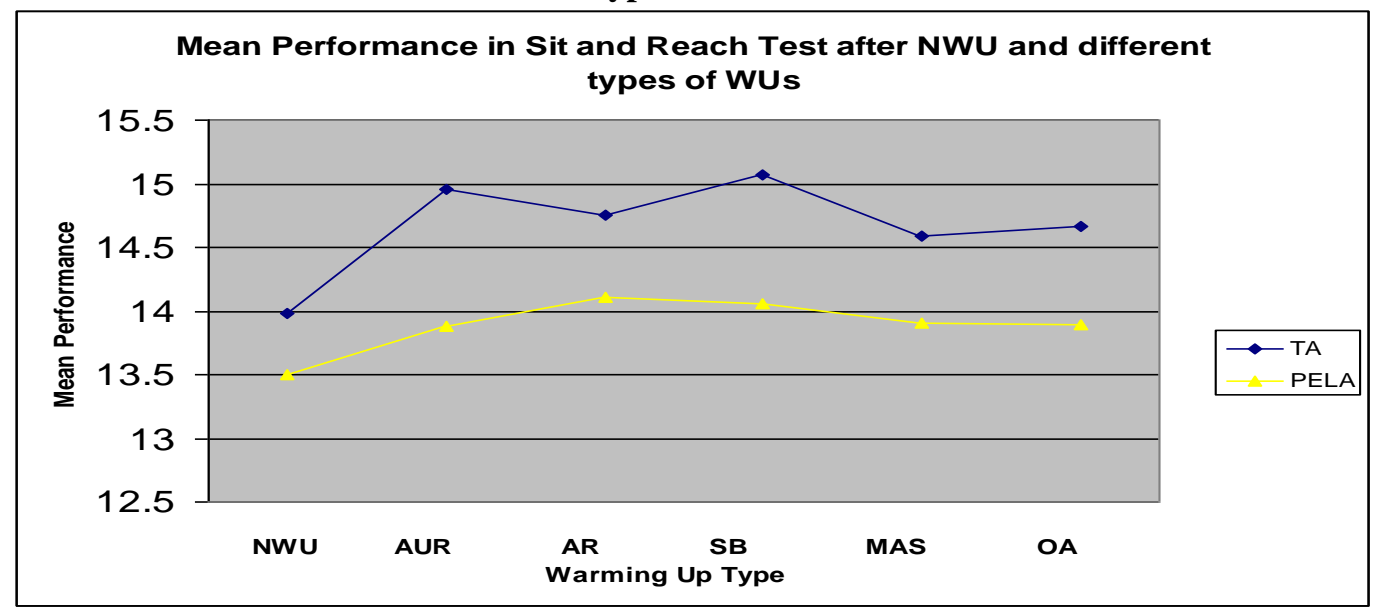

Fig No.-4 Comparison of Percentage increment in Pull ups Performance Of two groups.

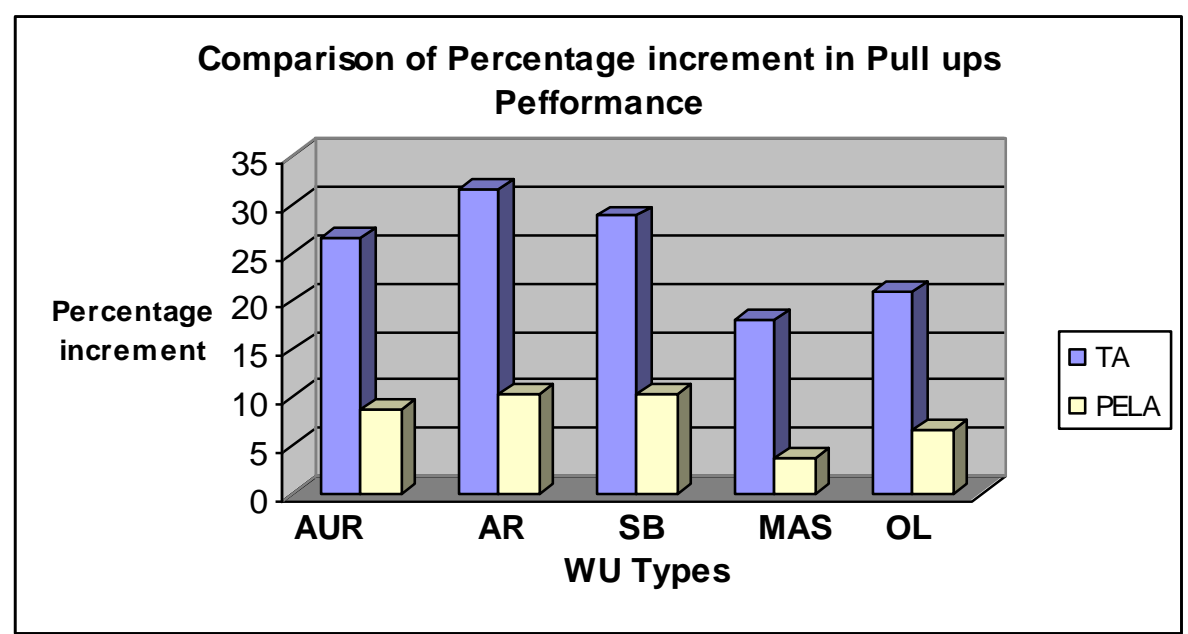

Fig No.-5 Comparison of Percentage increment (decrement in time) in Shuttle Run performance of two groups.

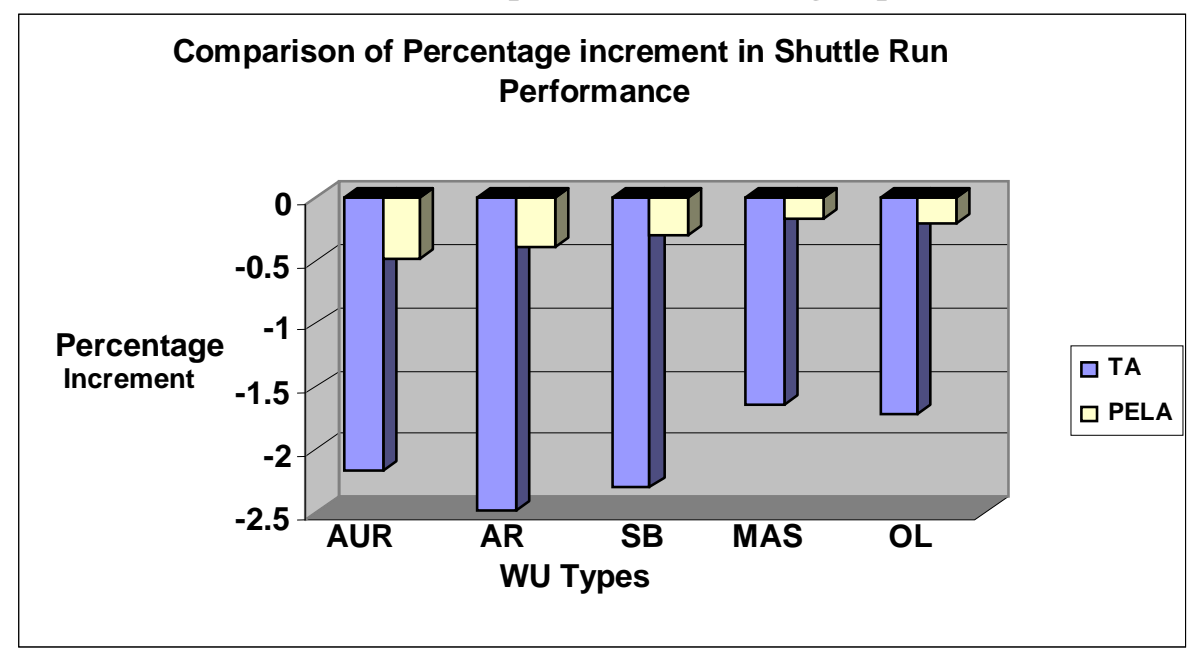


Fig No.-5 Comparison of Percentage increment in Sit \& Reach performance of two groups.

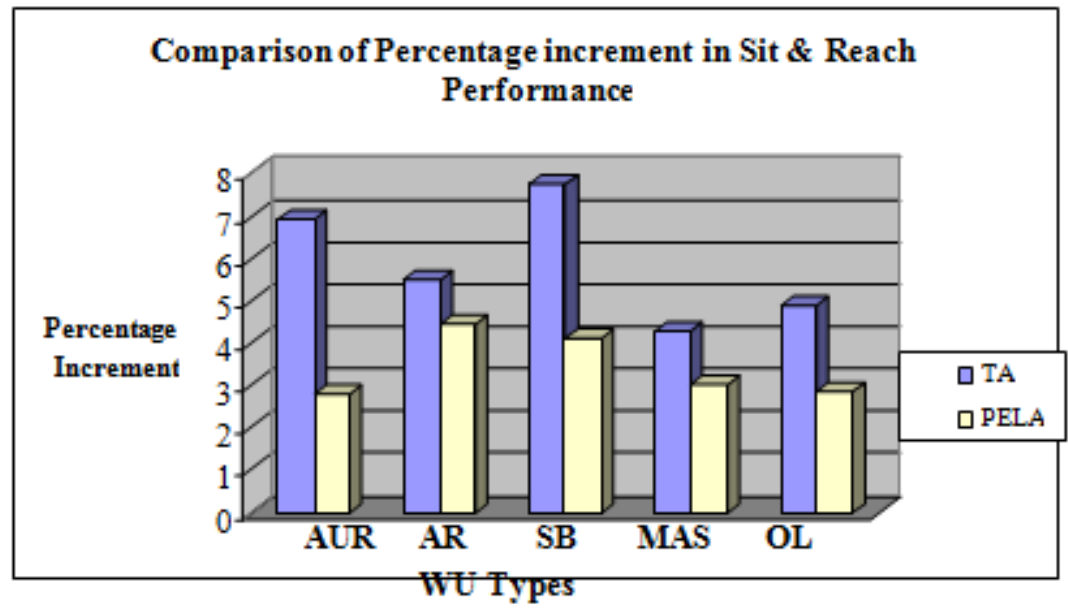

Results indicated that AR and SB conferred a considerable performance enhancement for all Pull ups performance relative to NWU as well as AUR and MAS also. Present study revealed that the influence of warming up was greater on TA (Fig. No.-1, 2 \& 3)) group in comparison to PELA. PELA group showed low performance increment due to AR as well as AUR in comparison (Fig.-4,5 \& 6) to TA. PELA group also showed some performance increment due to active as well as passive WU. In case of TA best performance was observed at AR and was significantly better than other two conditions except AUR and SB.(i.e. NWU and MAS). For PELA best performance was observed at AR, and was significantly better than NWU and MAS only. But performance at MAS is found to be not significantly better than performance at NWU so far as of pull ups test data of PELA subjects are concerned. On the basis of performance TA group may be arranged as $\mathrm{AR} \geq \mathrm{SB} \geq \mathrm{AUR}>\mathrm{MAS}>\mathrm{NWU}$. On the basis of performance PELA group may be arranged as $A R \geq S B \geq A U R>M A S \geq N W U$. Finally, it may surely be concluded that $A R$ and $S B$ conferred a considerable performance enhancement for all Pull ups performance relative to NWU as well as AUR and MAS also, but PELA group showed low performance increment due to AR as well as AUR in comparison to TA. Different researchers like Asmussen and Boje (1945), Gregson, et al.(2002), Grose (1958), Bergh and Ekblom (1979), Binkhorst, et al. (1977), Clerk, et al. (1958), Davies and Young (1983), Ranatunga, et al.(1980), Grose (1958) and so on studied the performance of trained, moderately trained and untrained male under various WU conditions and they showed performance increment in isometric force, vertical jump height, hand grip strength, finger strength, knee extension etc at exercise, hot water shower, hot bath, diathermy etc in comparison to no WU. They also showed best performance increment for trained than moderately trained and untrained. These findings are very much consistent with the present study. Results indicated that AR and SB conferred a considerable performance enhancement for all Shuttle Run performance relative to NWU as well as AUR and MAS also. Present study revealed that TA group ( Fig.-4,5 \& 6) has shown more performance enhancement due to AR and other WU conditions so far as Shuttle Run performance was concerned. But this increment was lower than Pull ups. For TA best performance was observed at AR, but post hoc test showed it was not significantly better than other four conditions except MAS and NWU. For PELA best performance was observed at SB, but post hoc test showed it was not significantly better than other conditions except NWU and MAS. PELA group showed low performance increment due to AR as well as AUR in comparison to TA. But PELA group also showed some performance increment due to active as well as passive WU. On the basis of performance TA group may be arranged as $\mathrm{AR} \geq \mathrm{SB} \geq \mathrm{AUR} \geq \mathrm{MAS}>\mathrm{NWU}$ and PELA group may be arranged as $\mathrm{SB} \geq \mathrm{AR} \geq \mathrm{AUR} \geq \mathrm{MAS} \geq \mathrm{NWU}, \mathrm{AR}>\mathrm{NWU}$ and $\mathrm{SB}>\mathrm{MAS}>\mathrm{NWU}$. In case of Sit \& Reach performance some unusual result, in comparison to other motor performance, was found (Fig.-1 to 6). Here, two groups showed performance increment due to active as well as passive WUs, but more consistent result was shown in case of PELA ( Fig.-1 to 6) than TA. Results indicated that AR and SB conferred a considerable performance enhancement for all Sit \& Reach performance relative to NWU as well as AUR and MAS also. TA group showed low performance increment due to AR, SB as well as AUR in comparison to PELA. An amazing fact was that, there was found no effect of passive WU on the performance of TA in comparison to NWU. Statistical analysis provided significant differences between performance at NWU and all other warming up performances. At the same time it showed that performance in Sit and Reach was significantly improved by AUR, AR, SB as well as MAS in comparison to NWU, but there was found no significant influence of AUR over AR, AUR over SB, AUR over MAS and AR over SB in respect to Sit and Reach test data of PELA subjects. It was found significant influence of AR over MAS and also SB over MAS in respect to same data. It may finally be concluded that for TA active and passive WU has some influence on motor performance in respect of NWU, but 
this influence is not significant for all cases. The mean magnitude of increment of sit and reach performance due to active as well as passive WU is found low due to extreme performance by some subjects in NWU case. Previous research has shown it possible to obtain the increased range of motion associated with stretching following a general warm-up. Zakas, et al.(2003) found that a general warm-up (20 minutes of jogging) alone increased range of motion through only the ankle dorsiflexion joint. Meanwhile, passive stretching (either following the general warm-up or alone) was found to increase range of motion in trunk flexion and each of the lower extremity joints measured in the study (Zakas, et al., 2003). Additional research suggests the increased range of motion may not immediately diminish after the stretch. Wenos and Konin (2004) found that a warmup as short as four minutes in length, but that could maintain $60 \%$ of one's heart rate reserve, could maintain hamstrings flexibility gains up to fifteen minutes following a prioproceptive neuromuscular facilitation (PNF) stretch intervention (Wenos and Konin, 2004). The present study is very much consistent with the above findings.

\section{Conclusion:}

In case of TA best performance was observed at $\mathrm{AR}$ and is significantly better than other two conditions except AUR and SB.(i.e. NWU and MAS). For PELA best performance was observed at AR, and was significantly better than NWU and MAS only so far as strength and agility component were concerned. It may finally be concluded that for TA active and passive WU has some influence on motor performance in respect of NWU, but this influence is not significant for all cases. The mean magnitude of increment of sit and reach performance due to active as well as passive WU is found low due to extreme performance by some subjects in NWU case.

\section{References}

[1]. Alter, M.J. (2004). Science of Flexibility. Champaign: Human Kinetics Inc.

[2]. Anshel, M.H.., \& Wrisberg, C.A. (1993). Reducing warm-up decrement in the performance of tennis serve. Journal of Sport and Exercise Physiology, 15, 290-303.

[3]. Arnett, M.G. (2002). Effects of prolonged and reduced warm-ups on diurnal variation in body temperature and swim performance. The Journal of Strength \& Conditioning Research, Volume: 16, Issue: 2, Pages: 256-261.

[4]. Arnold, G.N., Driscoll, N.M., Landin, D.K., Young, M.A. and Schexnayder, I.C. (2005). Acute effects of passive muscle stretching on sprint performance. Journal of Sports Sciences, May; 23(5): 449 - 454.

[5]. Asmussen, E. and Bonde-Petersen, F. (1974). Storage of elastic energy in skeletal muscles in man. Acta Physiologica Scandinavica 91 , pp. 385-392

[6]. Astrand, P. O., Rodahl, K., Dahl, H. A., \& Stromme, S. B. (2003). Text Book of Work Physiology (4th Edition).

[7]. Berge, U. and Ekblom, B. (1979).Physical performance and peak aerobic power at different body temperatures. . of Appl. Physiol. 46:885-889.

[8]. Binkhorse, R.A. et al.(!977). Temperature and force-velocity relationship of human muscles. J Appl Physiol; 42(4); 471-5.

[9]. Bishop, D., Bonetti, D., \& Dawson, B. (2001). The effect of three different warm up intensities on kayak ergometer performance. Med Sci Sports Exerc., 33(6): 1026-32.

[10]. Bishop D. (2003).Warm up I: potential mechanisms and the effects of passive warm up on performance. Sports Med 33: 439-454.

[11]. Brown, P.I., Hughes, M.G., \& Tong R.J. (2008). The effect of warm-up on high-intensity, intermittent running using nonmotorized treadmill ergometry. The Journal of strength and conditioning research: the research journal of the NSCA, ISSN 10648011, Vol. 22, $N^{o} .3$, pages. $801-808$.

[12]. Burkett, L.N., Ziuraitis, J., \& Phillips, W.T. (2001). The Effect of Four Different Warm-ups on the Maximum Vertical Jump Test Scores for Female College Athletes. Women in Sport \& Physical Activity Journal, September 22.

[13]. Burnley, M., Jones, A.M., Carter, A., and Doust, J.H. (2004).Effects of active distance on energy expenditure during simulated competition prior heavy exercise on phase II pulmonary oxygen uptake. J. Sports Med. 25:198-204.

[14]. Burnley, M., Doust, J. H., \& Jones, A.M. (2005). Effects of prior warm-up regime on severe intensity cycling performance. Medicine and Science in Sports and Exercise, 37(5), Supplement abstract 437.

[15]. Elbel E.R, Mikols W.J. (1972). The effects of Passive or Active Warm-up upon certain physiological measures. Int. Z. angew, Physiol: 31, 41-52.

[16]. Erdman W.J., $\left(2^{\text {nd }}\right)$ and Stoner E.K. (1956). Comparative heating effects of moisture and hydro-collator hot packs. Arch Phys Med Rehabil 37: 71-74.

[17]. Evans, R.K., Parcell, A.C., Knight, K.L., Schulthies, S.S., \& Draper, D.O. (2001). Effects of warm-up prior to eccentric exercise on indirect markers of muscle damage. Medicine and Science in Sports and Exercise, 33(5), Supplement abstract 691s.

[18]. Gray S, Nimmo M.(2001). Effects of active, passive or no warm-up on metabolism and performance during high-intensity exercise. Journal of Sports Sciences, Volume 19, Issue 9 September 2001, pages $693-700$.

[19]. Gregson, et al. (2002). The influence of Pre-warming on physiological responses to soccer-specific intermittent exercise (Part III: Physiology and kinanthropometry). European Journal of Applied Physiology, 86, 526-533).

[20]. Grose, J.E. (1958). Dpression of muscle fatigue curves by heat and cold. Res Q Exere Sports, 29: 19-31.

[21]. Holmstrom, E. and Ahlborg, B. (2004). Morning warming-up exercise- effects on musculoskeletal fitness in construction workers. Dept. of Physical Therapy, Lund University, University Hospital, Lasarettsgatan \&, SE-221 85 Lund, Sweden.

[22]. Ranatunga,et al.(1987) Contractions of human skeletal muscle at different temperature. J Physiol;390;383-95.

[23]. Wenos, D.L., and Konin, J.G. ( 2004) Controlled warm-up intensity enhances hip range of motion. J. Strength Cond Res 18: 529533.

[24]. Zakas, A. et al. (2003). The effect of stretching during warming-up on flexibility of junior handball players. Journal of Sports Medicine and Physical Fitness, 43, 141-149. 